\title{
Experience on the Vascular Approaches for Hemodialysis in the EL ABBADI Mohamed Saâd Clinic in Casablanca
}

\author{
Balde Oumar Taibata ${ }^{1}$, Camara Soriba Naby ${ }^{2}$, Balde Abdoulaye Korse ${ }^{1}$, Diallo Amadou Djoulde ${ }^{1}$, \\ Camara Fode Lansana ${ }^{1}$, Balde Habiboulaye ${ }^{1}$, Barry Madiou ${ }^{1}$, Soumaoro Labile Togba ${ }^{3}$, \\ Fofana Husseine $^{3}$, Soumah Aboubacar Fode Momo ${ }^{4}$, Diakite Sandaly ${ }^{3}$, Camara Mariame ${ }^{5}$, \\ Camara Mohamed ${ }^{2}$, Diallo Asmaou ${ }^{2}$, Yombouno Ives ${ }^{2}$, Biro Diallo ${ }^{1, *}$ \\ ${ }^{1}$ Department of Visceral Surgery, Donka National Hospital, Gamal Abdel Nasser University of Conakry, Conakry, Guinea \\ ${ }^{2}$ Department of Visceral Surgery, Friendship Hospital Sino-Guinean of Kipe, Gamal Abdel Nasser de Conakry, Conakry, Guinea \\ ${ }^{3}$ Department of General Surgery, Ignace Deen National Hospital, Gamal Abdel Nasser University of Conakry, Conakry, Guinea \\ ${ }^{4}$ Department of Gynecology and Obstetrics, Ignace Deen National Hospital, Gamal Abdel Nasser de Conakry, Conakry, Guinea \\ ${ }^{5}$ Department of Anesthesy and Reanimation Ignace Deen National Hospital, Gamal Abdel Nasser de Conakry, Conakry, Guinea
}

\section{Email address:}

cnabysoriba@yahoo.com (C. S. Naby), taibataoumars@gmail.com (B. Diallo)

${ }^{*}$ Corresponding author

\section{To cite this article:}

Balde Oumar Taibata, Camara Soriba Naby, Balde Abdoulaye Korse, Diallo Amadou Djoulde, Camara Fode Lansana, Balde Habiboulaye, Barry Madiou, Soumaoro Labile Togba, Fofana Husseine, Soumah Aboubacar Fode Momo, Diakite Sandaly, Camara Mariame, Camara Mohamed, Diallo Asmaou, Yombouno Ives, Biro Diallo. Experience on the Vascular Approaches for Hemodialysis in the EL ABBADI Mohamed Saâd Clinic in Casablanca. Journal of Surgery. Vol. 8, No. 3, 2020, pp. 86-89. doi: 10.11648/j.js.20200803.12

Received: April 20, 2020; Accepted: May 21, 2020; Published: June 4, 2020

\begin{abstract}
The arteriovenous fistula (AVF) for hemodialysis, consists of surgically creating an anastomosis between an artery and a superficial vein in the arm. This study aims to mark our contribution to the study of arteriovenous fistulas for hemodialysis during our internship in Morocco Methodology: We carried out a six years retrospective study from January $1^{\text {st }}$, 1994, to December $31^{\text {st }}, 1999$, inclusively. The study involved 1,531 arteriovenous fistulas performed during our studying period on 2,361 consultations. All the adequate files were included in our study. The other inadequate files were excluded. Results: The study involved 833 , that is $44.8 \%$ of men and 698 , or $37.6 \%$ of women. Sex ratio 1.19 . Thus, we counted right radial FAV 388 cases; Ulnar FAV 5 cases; FAV of the elbow crease 137 cases. In the left upper limb, 1,321 procedures, or 71.1\%, distributed as follows: Left radial FAV 1,080 cases Cubital FAV 7 cases Elbow fold AVF 234 cases. According to the Vascular Seats (arteries and veins), the anastomoses were performed between Arteries and radial veins 388 or $20.9 \%$ Left radial arteries and veins 1080 cases or $58.1 \%$, Humero-basilica 194 or $10.4 \%$, Humero-cephalic 154 cases or $8.2 \%$. Anastomoses on ulnar and other arteries 2, 5\% straight 388 or 20.9\% Left radial arteries and veins Conclusion: For patients with end-stage chronic kidney disease, arteriovenous fistulas are the last hope for their survival.
\end{abstract}

Keywords: Fistula, Arteriovenous, Hemodialysis

\section{Introduction}

The arteriovenous fistula (AVF) for hemodialysis, consists of surgically creating an anastomosis between an artery and a superficial vein in the arm $[1,2]$.

The vein thus "arterialized" increases in size, its wall thickens, it becomes visible under the skin, and its puncture become easy.
In Switzerland, 2.2 million people suffer from a chronic condition, and almost $20 \%$ of the population aged $>50$ suffer from multiple chronic diseases [3]. The material costs of noncommunicable diseases are very high. In 2011, they represented $80 \%$ of all direct health costs in Switzerland, that is, more than 51 billion francs [4-7]. As in other developed countries, chronic renal failure (CKD) is intimately linked to modern-day diseases [8,9]. Consequence, an increase in its prevalence, estimated at 1 to 20 people according to Dutch 
and American forecasts [10].

The arteriovenous fistula (AVF) constitutes the last hope of life for the patient on hemodialysis [11].

Seemingly easy to do but really difficult to keep, FAV remains the domain of a specialist surgeon, capable of all acrobatics to give life to a desperate patient, by creating a "venous" pathway sufficient for hemodialysis.

Unfortunately, the facts are cruel because no FAV can give the guarantee of being final.

They are then morally and physically fragile patients, who undergo multiple repetitions until the complete exhaustion of their venous capital [12].

The survival of the fistula depends on several factors of which we can cite among others:

The quality of the vessels (arteries and veins) The etiology of renal failure systemic diseases. The quality of the anastomosis and that of the nursing staff [13].

Thus, the difficulties linked to the creation of fistulas and the fragile character of the patients are among other reasons the choice of this article.

\section{Materials and Method}

Our study was carried out in the office of Dr. EL ABBADI Mohamed Saâd, from Casablanca.

Our study materials consisted of patients admitted and operated for arteriovenous fistula for hemodialysis from 1994 to 1999 and pre-established survey sheets.

All the relevant files were included in the study.

No inadequate records were included in the study.

We have carried out qualitative and quantitative analyzes of our medical records.

All our patients have been informed about the need to create fistulas in order to give them better hope of survival.

Administrative procedures and patient confidentiality were respected. We had encoded the patients.

\section{Results}

Table 1. Distribution of patients according to the activities by year.

\begin{tabular}{lllllll}
\hline Years & $\mathbf{1 9 9 4}$ & $\mathbf{1 9 9 5}$ & $\mathbf{1 9 9 6}$ & $\mathbf{1 9 9 7}$ & $\mathbf{1 9 9 8}$ & $\mathbf{1 9 9 9}$ \\
\hline Total Consultations & 216 & 326 & 338 & 427 & 463 & 591 \\
FAV oven consultations & 97 & 160 & 197 & 286 & 356 & 435 \\
Total intervention acts & 130 & 241 & 299 & 553 & 585 & 709 \\
FAV interventions & 123 & 219 & 259 & 390 & 400 & 465 \\
\hline
\end{tabular}

Total acts $=3280$.

Total FAF 2,445 or $75.5 \%$.

Activities of the firm during the six years selected for the study: January $1^{\text {st }}, 1994$ - December $31^{\text {st }}, 1999$.

1) Total consultations $=2361$

2) FAV consultations $=1531$

3) Interventions for $F A V=1856$

Or 325 whose first consultations are made in other clinics

Table 2. Distribution of patients by age group.

\begin{tabular}{lllllllll}
\hline Age groups & $\mathbf{0 - 9}$ & $\mathbf{1 0 - 1 9}$ & $\mathbf{2 0 - 2 9}$ & $\mathbf{3 0 - 3 9}$ & $\mathbf{4 0 - 4 9}$ & $\mathbf{5 0 - 5 9}$ & $\mathbf{6 0}$ and over & totals \\
\hline Number of cases & 4 & 49 & 76 & 129 & 257 & 281 & 735 & 1531 \\
$\%$ & 0.2 & 3.2 & 4.9 & 8.4 & 16.7 & 18.3 & 48.8 & 100 \\
\hline
\end{tabular}

Table 3. Distribution of FAV by gender.

\begin{tabular}{lll}
\hline Sex & Number of cases & Percentage \\
\hline Male & 833 & $54.4 \%$ \\
Feminine & 698 & $45.6 \%$ \\
\hline
\end{tabular}

Sex ratio of 1.19

Table 4. Distribution of the patient according to the antecedent.

\begin{tabular}{lll}
\hline Background & Number of cases & Percentage \\
\hline HTA & 1401 & \\
Diabetes & 67 & \\
\hline
\end{tabular}

The state of the veins

The veins were

1) Normal In 1202 patients Calcified in 334 Hail patients in 49 patients Thrombosis in 18 patients.

2) 97 percent of our patients were on dialysis with a catheter before the creation of AVF.

Distribution of FAV according to the seat of the act

1. In the right upper limb, there are 530 acts or $28.5 \%$ distributed as follows:

a) Right radial FAV 388 Cubital FAV 5 Elbow crease FAV 137

2. To the top left member, 1,321 acts or $71.1 \%$, distributed as follows: b) FAV radial left 1080 FAV cubital 7 FAV of the elbow 234

3. Vascular seat (arteries and veins)

c) Straight radial arteries and veins 388 or $20.9 \%$

d) Left radial arteries and veins 1080 cases or $58.1 \%$

e) Humero-basilica 194 cases or 10.4\% Humero-cephalic 154 or $8.2 \%$

f) Anastomoses on ulnar and other arteries 2.5\%

In descending order, we note:

a) FAV radial left 1080 or $58.1 \%$

b) Right radial FAV 388 or $20.9 \%$

c) FAV of the fold of the left elbow 234 or $12.6 \%$

d) FAV of the bend of the right elbow 137 i.e., $7.3 \%$

The immediate result after fistula creation

a) This was palpable in 1,432 patients

b) Non-palpable thrill in 99 patients

c) Type of anesthesia

d) Local anesthesia

e) Regional loco

FAV resumes or complications

This is the place to present an example of this difficult situation concerning a 38-year-old patient upon admission to the office.

On February $5^{\text {st }}, 1997$, she underwent 11 recoveries: 
1. On 5/2/97, we gave her a left ulnar FAV.

2. 22/2/97 FAV of the fold of the left elbow and right humero-basilica bypass.

3. On $4 / 3 / 97$, all the anterior fistulas are non-functional with Thrombosis of the Humero-basilic bypass.

Act: Fogarty probe thrombectomy and angioplasty of the puncture points.

4. 24/3/97: Infection and exteriorization of bypass prosthesis.

Act: Resection of necrotic tissue and burial of the prosthesis.

5. 11/4/97: Rejection of the infected prosthesis.

Act: Removal of the prosthesis and restoration of the continuity of the humeral artery.

6. 4/28/97: False aneurysm on the humeral anastomosis.

Act: Resection of the aneurysm and repair of continuity by saphenous bypass.

7. 5/5/97: Rupture of the sapheno-humeral bypass.

Action: Restoration of continuity by bridging with saphenous vein.

8. 4/9/97: Left: Act: humero-basilica bypass by prosthesis.

9. 11/19/97: False aneurysm on the bypass on the left.

Act: Resection of the pocket and restoration of continuity.

10.11/25/97: False aneurysm on the bypass on the left.

Act: Resection of the aneurysm and anastomosis by the bypass.

11.8/12/97: Infection of the bypass on the left with a false aneurysm.

Act: Removal of the prosthesis and cure of the aneurysm.

\section{Comments}

From January $1^{\text {st }}, 1994$, to December $31^{\text {st }}, 1999,1,531$ patients were hospitalized and operated in the EL ABBADI Mohamed Saâd Clinic in Casablanca for arteriovenous fistula for hemodialysis, an annual frequency of 129 patients.

The creation of the AVF for hemodialysis represents 75 percent of the activities of this clinic. Table 2 .

The average age of the patients were 34 years with extremes of 9 years and 60 years. This confirms that terminal stage insufficiency can affect all age groups Table 2, our results agree with those of most publications (14.15.16.17.18).

The sex ratio of nearly 1.9 reflects a clear predominance of male affection.

This confirms that no FAV can give the guarantee to be final. The complications can be summarized by: nondevelopment, stenosis, Thrombosis, ischemia, aneurysm, infection and/or hyper flow. These fairly frequent complications, resulting in rather delicate situations for patients who think that an act must necessarily correspond to a satisfactory result; and for the Doctor who, to satisfy the patient, is sometimes obliged to spend out of his pocket to correct a complication, however independent of the act.

Note: the rise in the consultation curve and that of the firm's specialization in the creation of the FAV (table 1).
All ages are affected by acute or chronic diseases causing kidney failure and, therefore, hemodialysis.

The most affected age group is that of 60 years and over $(48.8 \%)$.

The active social layer, whose age is between 20 and 50 years, represents $30.1 \%$ of patients. ((Table 2$)$. The similarly result was found by many other authors [19-26].

The preference of the left upper limb is an indication of hemodialysis for patient convenience.

We can thus safely predict that the black series of this lady will continue until the complete exhaustion of all her venous capital.

Note that we voluntarily omitted the previous acts relating to the radial FAV and the catheter poses suffered by this patient. And her only hope remains her Doctor.

The preference of the left upper limb is an indication of hemodialysis for patient convenience [27-31].

The left upper limb is much more used than its right counterpart (3 times out of 4 ).

\section{Conclusion}

The arteriovenous fistula constitutes the last hope of life for the patient on hemodialysis.

This is how important it is to spare this fistula, the creation of which is the responsibility of a specialist surgeon with suitable instrumentation, therefore expensive for the patient and the structure that supports him, because of the fairly frequent complications.

Healthcare workers must, therefore, respect an arterialized vein, always keeping in mind that the patient's venous capital is most important.

\section{References}

[1] Robert G. Jones Robert A. Morgan, the Current Status of Percutaneous Endovascular Arteriovenous Fistula Creation for Hemodialysis Access Cardiovascular volume 42, pages 1-9 (2019).

[2] Jernej Lučev, Silva Breznik, Dejan Dinevski, Robert Ekart \&Mitja Rupreht Endovascular Treatment of Haemodialysis Arteriovenous Fistula with Drug-Coated Balloon Angioplasty: A Single-Centre Study Cardio Vascular and Interventional Radiology volume 41, pages 882-889 (2018).

[3] Bachmann N, Burla L, Zeltner T, Health in Switzerland Update on chronic diseases. Swiss Health Observatory, Neuchâtel, 2015.

[4] Ponte B., et al. Chronic renal failure: attitudes and practices for screening in the absence of randomized studies. Rev Med Switzerland 2010; 1400-1404.

[5] Gilbertson DT, et al. Projecting the number of patients with end-stage renal disease in the United States to the year 2015. J Am Soc Nephrol. 2005; 16 (12): 3736-41.

[6] YENA S; FONGORO S; SANOGO ZZ; MAIGA MK; SANGARE D; KEITA A; SIDIBE S; TOURE M; SOUMARE S. Arteriovenous fistula on hemodialysis. 
[7] VASCULAR APPROACH FOR HEMODIALYSIS: French association of nurses for dialysis, transplantation and nephrology. Masson Edition, ISBN: 2- 294-01363-8; Paris; 2004; page: 46-51.

[8] RYCKELINCK PH; HURAULT of LIGNY B; LEVALTIER B; E. LARDINEAU, Ch. LEGOFF and JM BATHO: Place of peritoneal dialysis in the treatment of end-stage renal disease. Patient survival and method. Nephrology; 1995; \# 1; p: 85-92.

[9] National Kidney Foundation. KDOQI Clinicat Practice Guidelines and Clinical Practice Recommendations for 2006 Updates: Haemodialysis Adequacy, Peritoneal Dialysis Adequacy and Vascular Access. Am J Kidney Dis 48: S1S322, 2006 (suppl. 1).

[10] Imsand D., Teta D., et al. Problems due to hemodialysis fistulas: a regional care network. Rev Med Switzerland 2009; 5: 294-8.

[11] Parisotto MT., Et al. Technical cannulation influences arteriovenous fistula and graft survival. Kidney International 2014; 86: 790-7.

[12] Sousa C. et al. Physical examination: How to examine the arm with arteriovenous fistula. Hemodialysis International 2013; 17: 300-306.

[13] Beathard, G. "Physical examination of mature hemodialysis arteriovenousfistula". UpToDate, 2013.

[14] Bourquelot, P. "Vascular approaches for hemodialysis". Continuous Medical Expertise in Nephrology. Nephrology \& Therapeutics. 2009; 5: 239-248. [15] Beathard, G. "Failure of the mature hemodialysis arteriovenousfistula." Up To Date, 2014.

[15] Allon, M. "Monitoring and surveillance of hemodialysis arteriovenousfistulas to prevent thrombosis". Up To Date, 2013.

[16] Asif A. et al. "Accuracy of physical examination in the detection of arteriovenousfistula stenosis". Clin J Am Soc Nephrol 2007; 2: 1191-1194.

[17] Sidway A. et al. The Society for Vascular Surgery: Clinical practice guidelines for the surgical placement and maintenance of arteriovenous hemodialysis access. J Vasc Surg 48: 2S-25S; 2008.

[18] Tessitore N. et al. In Search of an Optimal Bedside Screening Program for Arteriovenous Fistula Stenosis. American Society of Nephrology. 2011; 6: 819-826.
[19] Coentrão L. et al. Physical examination of dysfunctional arteriovenous fistulae by non-interventionalists: a skill worth teaching. Nephrol Dial Transplant 2012; 27: 1993-1996.

[20] Turmel, L.; et al. Diagnostic and interventional radiology of arteriovenous access for hemodialysis. Springer-Verlag France 2012; 2: 5-9.

[21] Campos R. et al. Stenosis in hemodialysis arteriovenousfistula: Evaluation and treatment. Hemodialysis International 10: 152-161; 2006.

[22] European Renal Association. European Best Practice Guideline on Haemodialysis (part 2.). Nephrology Dialysis Transplantation 2007; 22: 27-38. 1.

[23] Sousa C. et al. Physical examination of arteriovenous fistula: The influence of professional experience in the detection of complications. Hemodialysis International 2014; 18: 695-699.

[24] UK Renal Association. Clinical Practice Guidelines - Vascular Access for Haemodialysis. 6th edition, UK. March 2015.

[25] Ponce P., Pinto B. Measuring vascular access flow: the accuracy of different methods. Port J Nephrol Hypert 25 (2): $151-155 ; 2011$.

[26] Morin, D., and M. Eicher. "Advanced Nursing Practice." Swiss Medical Review - www.revmed.ch -, September 5, 2012: 1680-1681.

[27] Beathard, G. An Algorithm for the Physical Examination of Early Fistula Failure. Seminars in Dialysis 2005; Vol 18, No 4 (July-August): 331-335.

[28] D'Amour, D., Sicotte, C., \& Lévy, R. Collective action within interprofessional teams in health services. Social sciences and health $1999 ; 17$ (3): 67-94

[29] Swiss Academy of Medical Sciences. Charter: Collaboration between health professionals. 2014.

[30] Donabedian, A. An Introduction to Quality assurance in Health Care. New York: Ed. By Bashshur, R., Oxford University Press, 2003.

[31] Beathard, G. Physical Examination: The Forgotten Tool. Dialysis Access - A Multidisciplinary Approach. Edited by Gray R., Sands J., New York, Lippincott Williams \& Wilkins, 2002: 111-118. 